\title{
Wave attenuation by heterospecific coastal vegetation - modelling through response surface methodology on synthetic plant meadows
}

\author{
S. Hemavathi* and R. Manjula \\ Department of Civil Engineering, National Institute of Technology, Tiruchirappalli 620 015, India
}

\begin{abstract}
Understanding of the interactions between wave and aquatic vegetation is gaining importance mainly due to plant-induced wave attenuation phenomenon for developing sustainable coastal management systems. Most of the wave-vegetation interaction studies focus mainly on monotypic coastal plant meadows; however, studies on heterospecific plant meadows are limited. The present study is aimed to understand the heterospecific vegetation-wave interactions through a threelevel, four-factor response surface methodology using wave flume under controlled conditions. Heterospecific seagrass species, Halophila spinulosa and Halophila ovalis are simulated physically by means of synthetic plant mimics to develop a relationship between wave attenuation $(E \%)$ and four direct control factors, viz. water depth $(h)$, wave period $(T)$, plant density $(N)$ and bed roughness factor $(f)$ through an empirical model. The developed model was tested using analysis of variance technique, and analysed for main and interaction effects of the studied parameters. The results showed that all the considered parameters are significantly effective on $E \%$ individually as well as in combination. All the model-based results were compared with a new set of experimental data and tested for validation.
\end{abstract}

Keywords. Coastal vegetation, empirical modelling, flume experimentation, response surface methodology, synthetic plant meadows, wave attention.

SEA-LEVEL rise and land subsidence along the densely populated coastlines have been recognized as a major threat to coastal areas of many countries all over the world. Natural coastal ecosystems, such as seagrasses, salt marshes and mangrove forests provide a wide range of ecosystem services ${ }^{1-5}$ and act as vegetated foreshore structures ${ }^{6,7}$. These ecosystems potentially reduce the impact of surges and waves at places where they are situated in front of engineered flood defence structures. Vegetated foreshore structures are known to affect the local hydrodynamic climate ${ }^{8}$. They act as an interface between

\footnotetext{
*For correspondence. (e-mail: shemathiru@gmail.com)
}

oceans and dry land, reduce wave height, develop mixing layers $^{9}$ and control the intensity of turbulence due to both waves breaking in shallow water and wave attenuation by vegetation. This natural phenomenon has led to the concept of sustainable coastal protection with the use of seagrass meadows, salt marshes and mangrove forests as a natural coastal defence system. With ever-growing population and infrastructure along with the low-lying coastal areas, the potential of coastal vegetation to act as a bioshield or a non-intrusive buffer in order to mitigate the combined effects of sea-level rise and subsidence is of recent increased interest ${ }^{10}$.

The interaction between wave-vegetation is complex, since not only water flow affects vegetation and vice versa, but both may interact in highly coupled, nonlinear ways $^{11}$. Attenuation of a wave caused by vegetation is identified due to the force exerted by plants on moving water. Following Newton's third law, water simultaneously exerts a force equal in magnitude and opposite in direction on the plants. The flexibility of the plants determines how plant motion and wave motion interact, and determines the magnitude of the drag forces ${ }^{12,13}$.

The degree of attenuation depends on the plant characteristics such as plant height, plant stiffness, buoyancy, degrees of freedom, plant density, spatial configuration, and hydrodynamic wave parameters such as wave height, water depth, wave period, direction, etc. The variability of wave damping is too large such that a general standard procedure for a systematic study on 'plant-induced attenuation' has not yet been well established $^{14}$. There is often either a lack of knowledge due to the many varieties of vegetation related to different climatic conditions and their respective specific properties, or the insufficiency of modelling tools while taking vegetation into account ${ }^{15}$.

Many studies quantify wave attenuation by vegetation, based on field ${ }^{16-19}$, laboratory flume measurements $\mathrm{s}^{3,7,15,20-22}$ and numerical models ${ }^{9,14,23-25}$. The magnitude of wave attenuation depends on hydrodynamic parameters such as wave height ${ }^{26}$, wave period ${ }^{27}$ and water $\operatorname{depth}^{28}$ and on vegetation characteristics such as stem height, diameter and density ${ }^{28,29}$, and flexibility ${ }^{30}$. Nearly all these studies 
are related to monotypic aquatic plant meadows. However, limited work has been reported on heterospecific vegetation meadows, although it is well known that each seagrass species could occur as a heterospecific seagrass bed, an intermixture with the other species ${ }^{31}$. In North America, some seagrass beds even consist of all seven seagrass (Halophila) species scattered through a few areas within the bed ${ }^{34}$. This information is particularly important for the tropical shore regions, where some species of seagrass occur together in one meadow. For tropical shores of the Indian subcontinent, the heterogenous plant meadow comprises two of the major Halophila species, viz. H. spinulosa and $H$. ovalis, commonly found along the Gulf of Mannar ${ }^{26}$ and the coast of Tamil Nadu in southern India. The changes in wave vegetation mechanisms due to structural complexity of the heterospecific meadow involving different seagrass species are equally important which attracts attention from the scientific community to develop a sustainable coastal management system. In recent times, systematic studies on wave-vegetation interactions ${ }^{32}$ of aquatic plant meadows and the associated effect of control parameters on wave attenuation are gaining importance due to coastal hazards such as incessant surge storms, cyclones and the occasional tsunami ${ }^{33-35}$.

Moreover, the effect of seagrass bed characteristics composed of different species of seagrass on wave attenuation is not easy to analyse because of the large number of independent process control parameters involved. Thus a study involving heterospecific species in the tropical ecosystems, is of special interest. Here, we have developed an experimental, design-based empirical model for wave transformation over underwater heterospecific vegetation (Halophila species) in a laboratory flume. A three-level, four-factor, central composite design-based response surface methodology (RSM) was selected for the study. The major objectives were to (a) identify and select the operating limits for control parameters to carry out primary laboratory flume experimentation based on RSM; (b) develop a mathematical model to determine the effect of each of the selected process parameters for evaluation of their main and interaction effects on wave attenuation process, and (c) compare and validate the predicted results from the model with a new set of experimental data from secondary experimentation.

\section{Methodology, materials and data}

\section{Theory}

Several models on the attenuation of waves by vegetation are available in the literature, most of which are considered idealized, homogenous vegetation. Wave height reduction across a unit layer of vegetation has often been used to measure its ability to attenuate waves. The gene- ralized continuity equation within the aquatic vegetation is given by

$$
\frac{\partial u}{\partial x}+\frac{\partial w}{\partial z}=0
$$

Nobuhisa et $a l .{ }^{36}$ derived an analytical solution for smallamplitude monochromatic wave attenuation over submerged vegetation. Using the conservation of momentum principle, an expression for wave height reduction by an exponential function of the type is given by

$$
\frac{H_{x}}{H_{0}}=\mathrm{e}^{-K_{\mathrm{i}} \Delta x},
$$

where $K_{i}$ is the wave decay coefficient, $H_{x}$ the wave height along with vegetation canopy, $H_{0}$ the wave height in front of the leading edge of the canopy and $\Delta x$ is the distance of separation.

Augustin et al. $^{20}$ performed hydraulics-based experiments to measure the wave height decay through rigid and flexible cylindrical dowels. The methodology developed by Dalrymple et $a l^{37}$ was used to evaluate wave height decay in a vegetation field of three different densities, varying along the direction of wave propagation. Mullarney and Henderson ${ }^{38}$ used cantilever beam theory to derive a model for predicting vegetation motion due to wave forces. The proposed theory was compared with motions of a specific species of sedge in a natural salt marsh and was shown successfully with the tuning of a single parameter. A formula for wave height attenuation that includes vegetation motion was also developed. For linear waves, the general formula for the measurement of wave height when converted into energy density $(E)$ is given by

$$
E=\frac{1}{8} \rho g H^{2}
$$

where $\rho$ is the density of sea water, $g$ the acceleration due to gravity and $H$ is the wave height. Fonseca and Cahalan $^{39}$ calculated wave energy density reduction using the per cent reduction in energy density $(E \%)$ over a $1 \mathrm{~m}$ test section

$$
E \%=\left[\left(\frac{E(\text { in })-E(\text { out })}{E(\text { in })}\right) \times 100\right],
$$

where $E$ (in) is the energy density entering the $1 \mathrm{~m}$ test section and $E$ (out) is the energy density leaving the $1 \mathrm{~m}$ test section.

\section{Method}

The experiments were conducted in the wave flume at the Fluid Mechanic Laboratory, National Institute of 
Technology, Tiruchirappalli, Tamil Nadu, India. The wave flume has dimensions $12.5 \mathrm{~m}$ length, $0.3 \mathrm{~m}$ width and $0.6 \mathrm{~m}$ depth, and is equipped with an electrohydraulic piston wave generator on one side of the flume. Rubble masonry wave absorber with an aspect ratio of $1: 7$ was installed opposite the wave generator for avoiding wave reflection. A heterospecific artificial plant meadow of $1 \mathrm{~m}$ length was placed in the middle portion of the flume (Figure 1). The meadow started approximately $4 \mathrm{~m}$ from the wave paddle.

\section{Heterospecific vegetation conditions}

Halophila species is an aquatic seagrass plant that has roots, stems and leaves to form dense vegetative communities mostly in shallow-water estuaries ${ }^{40,41}$. It has a shorter leaf structure with blades that resemble tufts or whorls, thus differing from other seagrass species. The major seagrass species are Thalassia hemprichii, Halodule uninervis, Cymodocea serrulata, Cymodocea rotundata and Halophila ovata. Meadows of Halophila species and Syringodium isoetifolium generally occur in patches as mixed species ${ }^{31}$. The seagrasses of India consist of 14 species belonging to seven genera from approximately 50 species worldwide ${ }^{40}$. These species are found mostly in the Gulf of Mannar and Palk Bay along the southeast coast and the lagoons of islands from Lakshadweep in the Arabian Sea of the western part, to the Andaman and Nicobar in the Bay of Bengal of the eastern part of India.

The physical properties of the selected plants such as density and stiffness are important to study the wave interactions bending of the leaves and the resulting wave damping efficiency. For the present study, artificial models for the heterospecific Halophila meadow which includes $H$. spinulosa and $H$. ovalis (Figure $2 a$ ), made of plastic, were selected based on the most similar physical properties to real leaves such as modulus of elasticity, $E=0.9 \mathrm{GPa} . E$ and $\rho$, density of the plastic material used were $0.903 \mathrm{GPa}$ and $550-700 \mathrm{~kg} / \mathrm{m}^{3}$ respectively. A typical physical $H$. spinulosa has 10-20 pairs of leaves per shoot (15-20 mm long and 3-5 mm wide) arranged opposite to each other, and can be up to $15 \mathrm{~cm}$ long. H. ovalis, on the other hand, has cross veins, eight or more pairs of leaves that are 5-40 $\mathrm{mm}$ long and 5-20 $\mathrm{mm}$ wide ${ }^{31}$.

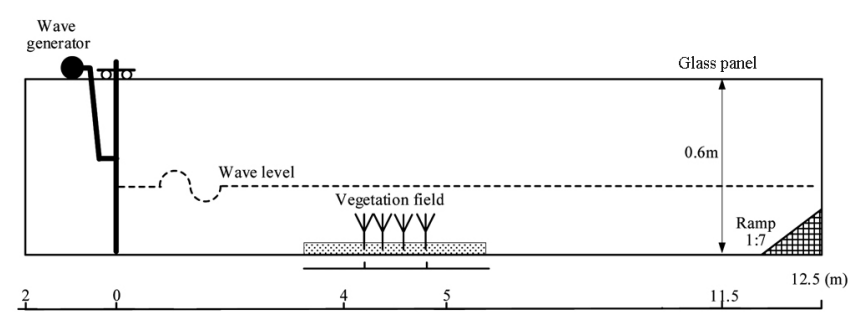

Figure 1. Details of the experimental set-up.
The artificial plants for $H$. ovalis have long leaves $(0.01 \mathrm{~m} \times 0.01 \mathrm{~m}$; Figure $2 \mathrm{~b})$. Each simulated plant consists of 6-10 leaves with a length of $0.01 \mathrm{~m}$. H. spinulosa is represented by $0.003 \mathrm{~m}$ diameter plastic stripes of length $0.01 \mathrm{~m}$. Both mimics were placed on a $1 \mathrm{~m} \times$ $0.26 \mathrm{~m}$ staggered plastic base plate and pasted to the metallic flume bed in a staggered distribution with a spacing of $43 \mathrm{~mm}$ apart to keep plant density at $543 \mathrm{stems} / \mathrm{m}^{2}$. Similarly, a spacing of $21.5 \mathrm{~mm}$ was kept for maintaining a plant density of $2163 \mathrm{stems} / \mathrm{m}^{2}$. The experimental run and wave profiles were recorded (Digital HD Video Camera Recorder SONY, Model No: HDR-PJ50V) with a sampling frequency of $25 \mathrm{~Hz}$. The recorded video images were processed using MATLAB image processing tool, and wave profile time series was obtained. Wave height before and after the meadow was used to compute the attenuation of waves.

\section{Central composite design}

The design of experiments (DOE) has been widely used and efficient statistical method for planning experiments, based on multivariate second-order models. A standard RSM design, viz. central composite design (CCD) method was applied in the present study to determine the regression model equations from the data obtained. The developed regression equations are useful in studying the interactions of the input parameters that affect the process. Valid and objective conclusions were drawn from the analysis of the regression equations to ensure the efficacy of the experiments. It is also useful in studying the interactions of various parameters affecting the process.

The DOE procedure starts with the identification of input variables and output (response) that is to be measured followed by three major steps: (1) selection, planning and execution of the most appropriate statistically designed experiments; (2) developing a mathematical model by estimating the coefficients, and (3) analysis and prediction of the response and checking the adequacy of the model ${ }^{42}$. The RSM involves establishing a correlation between the $k$ variables through a second-order polynomial expression. The true relationship between the
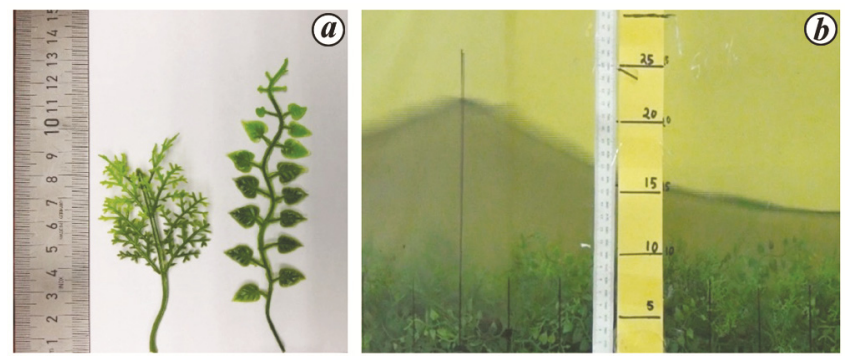

Figure 2. Artificial plants of Halophila spinulosa and Halophila ovalis. $\boldsymbol{a}$, Morphological features; $\boldsymbol{b}$, Inside the laboratory flume. 
Table 1. Original and coded values of control variables

\begin{tabular}{|c|c|c|c|c|c|c|}
\hline \multirow[b]{2}{*}{ Control variables } & \multirow[b]{2}{*}{ Unit } & \multirow[b]{2}{*}{ Notation } & \multirow[b]{2}{*}{ Coded symbol } & \multicolumn{3}{|c|}{ Original value of coded levels } \\
\hline & & & & -1 & 0 & +1 \\
\hline Water depth & $\mathrm{m}$ & $h$ & $\beta_{1}$ & 0.10 & 0.125 & 0.150 \\
\hline Wave period & s & $T$ & $\beta_{2}$ & 1.0 & 2.0 & 3.0 \\
\hline Plant density & stems $/ \mathrm{m}^{2}$ & $N$ & $\beta_{3}$ & 543 & 1353 & 2163 \\
\hline Bed roughness factor & - & $f$ & $\beta_{4}$ & 0.010 & 0.017 & 0.025 \\
\hline
\end{tabular}

Table 2. Estimated regression coefficients

\begin{tabular}{lc}
\hline Factors & Estimated coefficients \\
\hline Intercept & 51.94 \\
$h$ & -22.36 \\
$T$ & -15.58 \\
$N$ & 3.40 \\
$f$ & 5.35 \\
$h^{2}$ & $\underline{0.14}$ \\
$T^{2}$ & -10.26 \\
$N^{2}$ & 14.24 \\
$f^{2}$ & -23.44 \\
$h^{*} T$ & 14.36 \\
$h^{*} N$ & -1.20 \\
$h^{*} f$ & -5.37 \\
$T^{*} N$ & $\underline{-0.20}$ \\
$T^{* f}$ & 3.37 \\
$N^{*} f$ & $\underline{-0.61}$ \\
\hline
\end{tabular}

independent control variables or factors, $x_{1}, x_{2} \ldots x_{k}$ and the response $Y$ (dependent variable) can be represented by the following expression

$$
Y=f\left(x_{1}, x_{2}, \ldots, x_{k}\right),
$$

where $f$ is the unknown true response function of a system. For RSM, to establish an approximate function between the variables and the response functions through a designed series of experiments and statistical analysis, the most common model is the polynomial, based on Taylor series expansion. The second-order nonlinear polynomial equation to fit the data is given as follows ${ }^{42}$

$$
Y=\beta_{0}+\sum_{i=1}^{k} \beta_{i} x_{i}+\sum_{i=1}^{k} \sum_{j=1}^{k} \beta_{i j} x_{i} x_{j}+\sum_{i=1}^{k} \beta_{i i} x_{i i}^{2}+\varepsilon,
$$

where $Y$ is the predicted response (wave attenuation performance, $E \%$ in the present case), $X_{i}$ and $X_{j}$ the independent coded variables, $k$ the number of factors, $\beta_{0}$ the model constant term, $\beta_{i}, \beta_{i i}$, $\beta_{i j}$ the linear, square and interaction effect respectively, and $\varepsilon$ is the random experimental error. For the present study, face-centred central composite design (FCCD) approach was used to evaluate and analyse the linear, quadratic and interaction effects of the variables. Based on the results from a previous study, four major variables, viz. water depth $(h)$, wave period $(T)$, plant density $(N)$ and bed roughness factor $(f)$ were selected along with three levels of each variable, with ' -1 ', ' 0 ' and ' +1 ' denoting the low, middle and high levels of the factors respectively (Table 1).

For instance, steel surface, fine sand and coarse pebbles were used in the experiments to represent the low, middle and high levels of bed roughness respectively. FCCD method by definition requires 30 experimental runs and with three replications, there were 90 experiments in total, performed in a random order to eliminate systematic errors. For statistical analysis of the experimental data and their response surface graph, a statistical software (Minitab ${ }^{\circledR}$ software release 17, Inc., State College, PA) was used. Regression analysis was performed on the obtained data to identify the attribution effects of the selected variables on the predicted response $E \%$. The simulated seagrass meadow for $H$. spinulosa and $H$. ovalis was built with plastic as a series of modules on-board, and was fixed firmly together and to the floor of the flume. Between the flume walls and the meadow, sufficient gap was provided to enable free movement of the plant mimics, such that it allowed a better representation of actual seagrass meadow dispersion in shallow water $^{31}$.

\section{Results}

Tables 2 and 3 present the design matrix for the replicated experimental results and the obtained data respectively. Statistical software was used to (a) study the regression analysis of experimental data; (b) fit a nonlinear quadratic model, and (c) draw the response surface plots. The statistical parameters were estimated using ANOVA (analysis of variance) technique. The developed empirical model in terms of a coded factor for predicting $E \%$ is shown in eq. (7).

$$
\begin{aligned}
Y=\beta_{0} & +\beta_{1} h+\beta_{2} T+\beta_{3} N+\beta_{4} f+\beta_{1,2} h T+\beta_{1,3} h N \\
& +\beta_{2,3} T N+\beta_{2,4} T f \ldots+\beta_{1,1}(h)^{2}+\beta_{2,2}(T)^{2} \\
& +\beta_{3,3}(N)^{2}+\beta_{4,4}(f)^{2},
\end{aligned}
$$

where $\beta_{0}$ is the average of the responses, and $\beta_{0}, \beta_{1}$, $\beta_{3}, \ldots, \beta_{44}$ are regression coefficients that depend on the corresponding linear, interaction and quadratic terms of the factors ${ }^{42}$. The value of each coefficient was calculated using the software. Table 2 shows results of the regression coefficients for the second-order response surface 
RESEARCH ARTICLES

Table 3. ANOVA test results for $E \%$

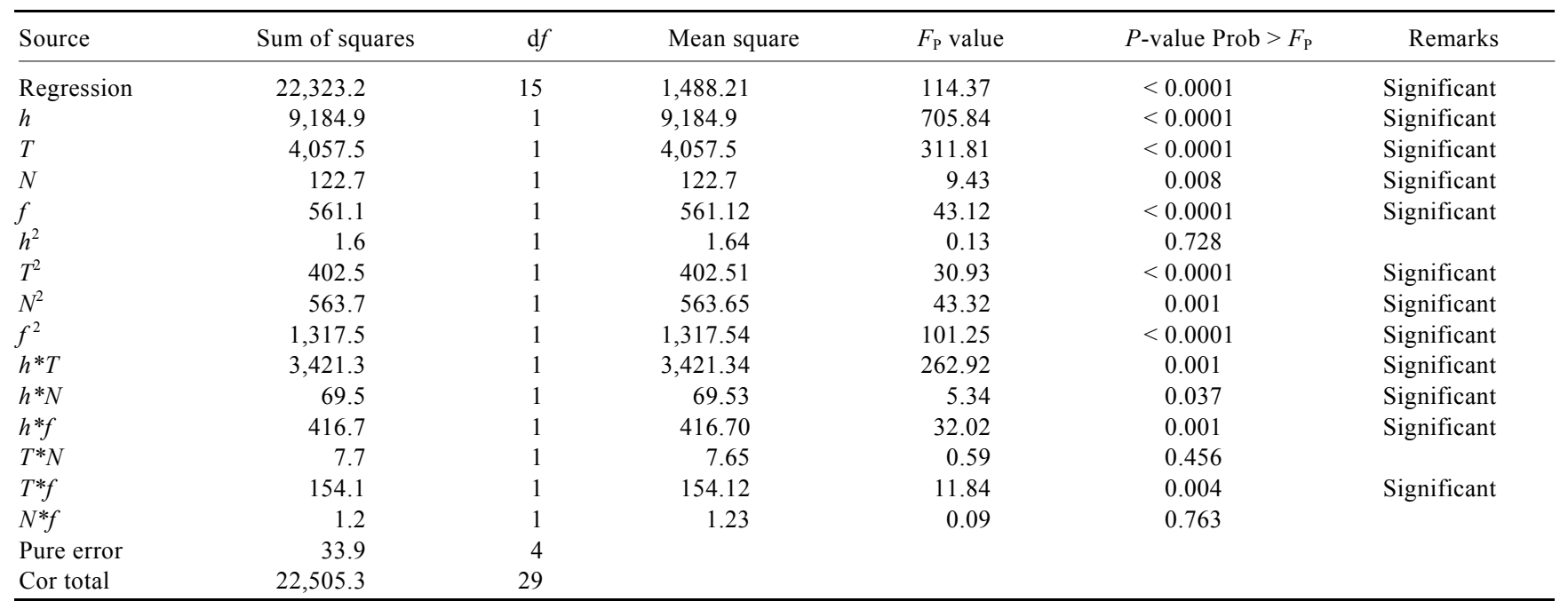

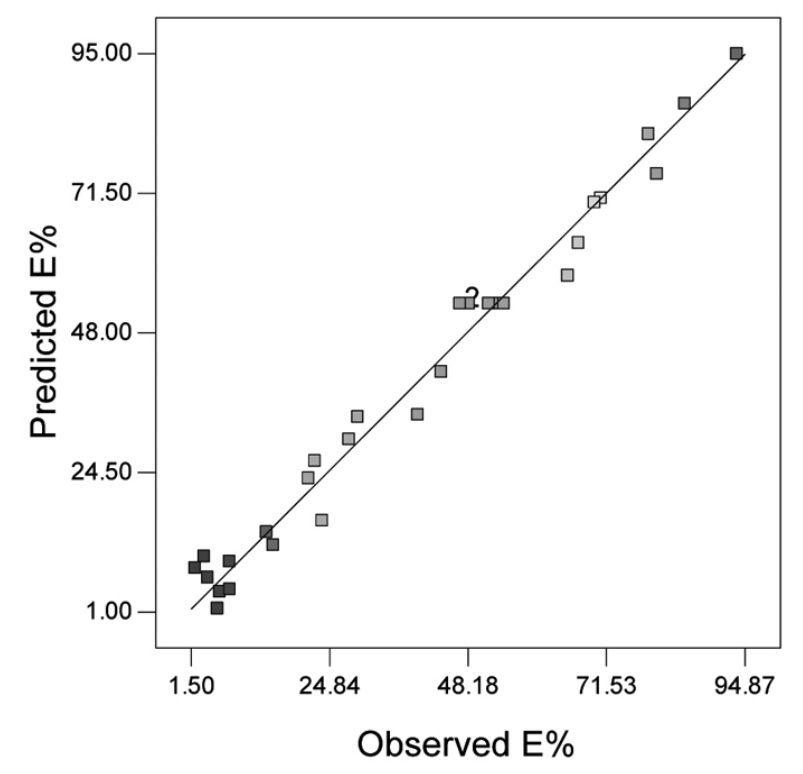

Figure 3. Comparison between predicted and experimental $E \%$ values.

model. The final empirical model developed using these coefficients is given in eq. (8)

$$
\begin{aligned}
& E \%=51.94-22.36 h-15.58 T+3.40 N+5.35 f \\
& \quad+14.36 h * T-1.20 h * N-5.37 h * f+3.37 T * f \\
& \quad-10.26(T)^{2}+14.24(N)^{2}-23.44(f)^{2} .
\end{aligned}
$$

The adequacy and statistical significance of the developed quadratic model for the response $(E \%)$ were tested using ANOVA. Table 3 shows the results. The coefficient of multiple determination $\left(R^{2}\right)$, for the developed quadratic model, was found to be large (0.983), which implies that only a total variation of 0.017 cannot be indicated by the model. The lack-of-fit $F$-value for the model was found to be 5.05 (not shown in the table), implying that the lack of fit is significant. This large value could occur due to noise. The predicted $R^{2}$ value of 0.887 was in reasonable agreement with the adjusted $R^{2}$ value of 0.965 . The adequate precision value measures the signal-to-noise ratio. A ratio greater than 4 is desirable. For the present model, the ratio of 24.464 indicates an adequate signal, and hence the developed model can be used to navigate the design space. A new set of experiments was conducted for validation of the developed regression model under similar experimental conditions. The collected data were plotted against those from the developed regression model (Figure 3). Each predicted value from the developed model matched well with the experimental value.

For the developed regression model, the large $F$ value (51.94, Table 2) and the associated lesser $P$-value (less than 0.0001, Table 2) indicate that the model and the model terms are statistically significant. The effect of model terms that are associated with $P$-values greater than 0.05 is statistically insignificant. In this case, Table 3 shows that all the linear terms $h, T, N$ and $f$, the quadratic terms $(T)^{2},(N)^{2}$ and $(f)^{2}$ along with the interaction terms $(h)^{*}(T),(h)^{*}(N),(h)^{*}(f)$ and $(T)^{*}(f)$ are significant for the response $E \%$. In the given design range, the quadratic terms $(h)^{2}$ and the interaction terms $(T)^{*}(N)$ and $(N) *(f)$ possess insignificant effects (underlined in Table 2 ). The sensitivity level of significant terms for $E \%$ from large to small is the linear term $h$, the interaction term $(h)^{*}(N)$, the linear term $(T)$, the quadratic term $(N)^{2}$, the linear term $f$, the interaction term $(h)^{*}(f)$, the quadratic term $(T)^{2}$, the linear term $N$, and the quadratic term $(f)^{2}$. From a comparison of statistical results, the linear term was most significant, the interaction term is the second most significant, and the quadratic term is least significant for $E \%$. These statistical results clearly indicate that the water depth $h$ has a definite linear relationship with $N$ and $T$, while $f$ has a nonlinear relationship with wave attenuation. 


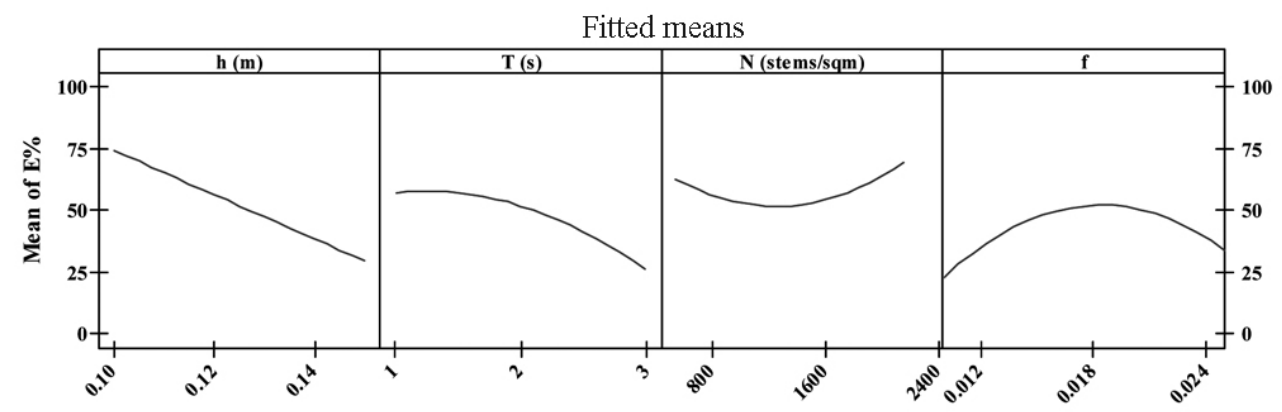

Figure 4. The main effect of model parameters on $E \%$.

\section{Parameter effects}

The results from the $F$-statistics probability value ( $P$ less than 0.05) imply that a good correlation between input and output variables could be drawn by the model developed in eq. (8). Parametric variables $h, T, N$ and $f$ play an important role individually on vegetation-induced wave attenuation. Figure 4 is a graphical representation of the main effects of statistically significant factors with their respective regression model-based magnitude and direction on the response $(E \%)$. It indicates that among the linear coefficients, $h$ and $T$ have inverse effects, while $N$ and $f$ have direct effects on $E \%$. It is well-accepted that under steady flow conditions, vegetation induced wave attenuation is a function of plant characteristics such as plant geometry, density, meadow coverage, mechanical properties, especially stiffness, buoyancy as well as hydrodynamic conditions, including water depth, wave height and wave period ${ }^{26}$. The results from the present study are in good agreement with most of the laboratory flume, field and modelling-based studies, confirming the dependency of wave-vegetation interactions on water depth $(h)^{2,26,39,43}$, wave period $(T)^{16,26,27,38,43-45}$, plant density $(N)^{12}$ and bed roughness factor $(f)^{2,43,46,47}$. In general, the surface wave attenuation is caused by the drag (energy loss) through work performed on the stems of both emergent and submerged vegetation ${ }^{48}$.

\section{Interaction effects of model parameters}

The interaction effects of all the statistically significant tested variables on $E \%$ over the vegetation meadow have been graphically represented here. The plots illustrate that the two-way interaction effect of water depth $h$ when combined with each of the three other considered parameters $T, N$, and $f$ is linearly proportional to the response $E \%$. The rest of all possible statistically significant twoway interactions among the considered control parameters $(T-N, T-f$ and $N-f)$ are nonlinear on $E \%$. The two-way interactions involving the wave period $T(T-N$ and $T-f)$ have an inverse relationship with a downward-sloping curve, while the $N-f$ interaction has a direct relationship with an upward sloping curve.
Interaction effect of water depth and wave period: Figure $5 a$ and $b$ shows the interaction effect of water depth $h$ and wave period $T$ on $E \%$ in the vegetation field. Here, $E \%$ is plotted for a plant stem density $N\left(1353 \mathrm{stems} / \mathrm{m}^{2}\right)$ and a friction factor $f(0.0175)$. At lower $h(0.11 \mathrm{~m})$ and $T$ ( $1.5 \mathrm{~s}), E \%$ is maximum (94\%), and increasing the water depth and wave-period results in a reduction of energy loss as the waves travelled along the vegetation zone, even though $E \%$ decreases to as low as $25 \%$ at the upper limit of $h . E \%$ rises with the wave period for small values of $T$ to a point and reduces gradually for large values of $T$ as it travels through the vegetation field. It could be attributed to the wider changes in coefficients of empirical wave decay for short peak wave periods, and nearly converging for longer $T$. Also, the theoretical wave decay coefficients were found to be nearly independent of the peak periods under dips during fluctuations. This is in agreement with the study by Huang et al. ${ }^{49}$, indicating that vegetation density and incident wave height are the two factors that mostly control the wave transmission coefficients.

Interaction effect of water depth and plant density: The developed regression model (eq. (8)) indicates that the interaction between $h$ and $N$ causes a negative effect on $E \%$, although the plant density $N$ makes a positive effect individually. Figure $6 a$ and $b$ shows the interaction effect as a function of water depth $h$ and plant density $N$ on $E \%$ at constant values of wave period (2s) and friction factor (0.0175). E\% increases with decreasing $h$ and increases with increasing $N$. However, Figure $6 a$ illustrates that the interaction effect between $h$ and $N$ causes negative behaviour, such that invariably with the increase of $N$, the increase in $h$ causes a decreasing trend in $E \%$. An increase in plant density $N$ from 543 to 2163 stems $/ \mathrm{m}^{2}$ causes $E \%$ to increase from $82 \%$ to $90 \%$. This result is in agreement with some published results ${ }^{12}$, although published results on the intensity of the effect of plant density on wavevegetation interactions are inconsistent. The literature shows contradictory results, as some studies have claimed that higher plant density causes no effect ${ }^{20,39}$, while another study shows improved wave dissipation ${ }^{12}$. However, it has been generally recognized that plant 

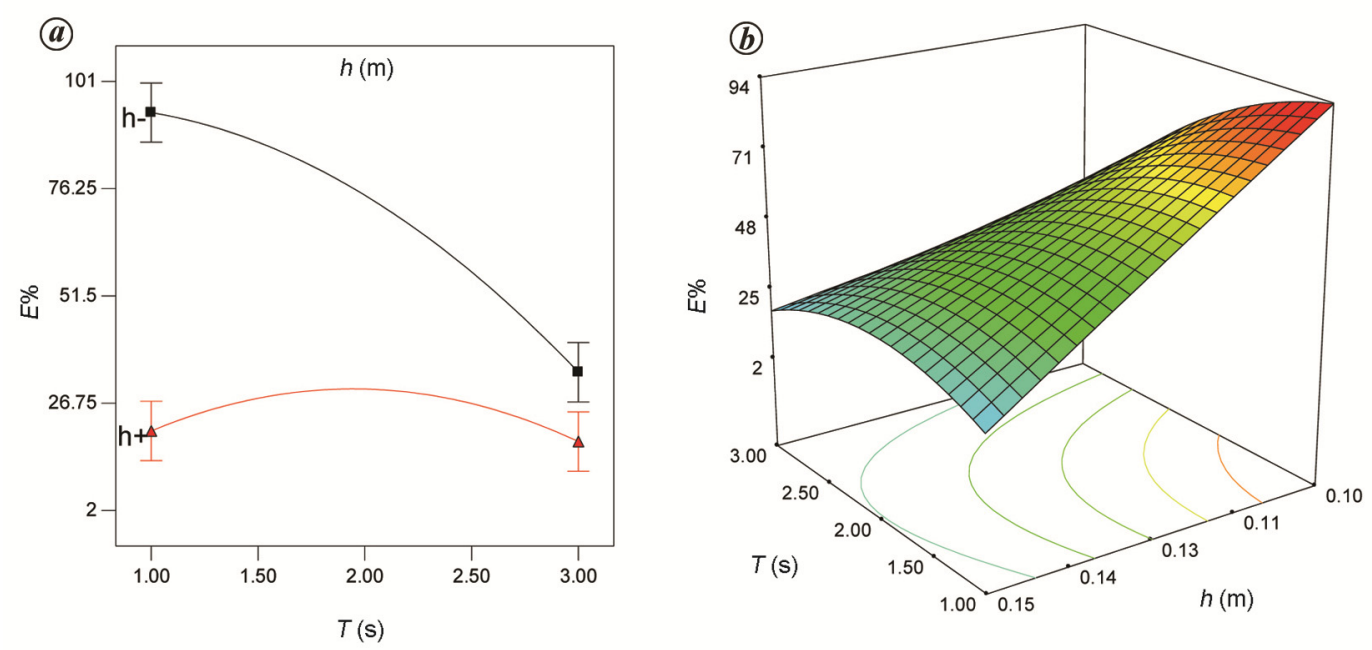

Figure 5. Interaction effect of $h$ and $T$ on $E \%$, $\boldsymbol{a}$, Two-way interaction effect; $\boldsymbol{b}$, Surface plot.
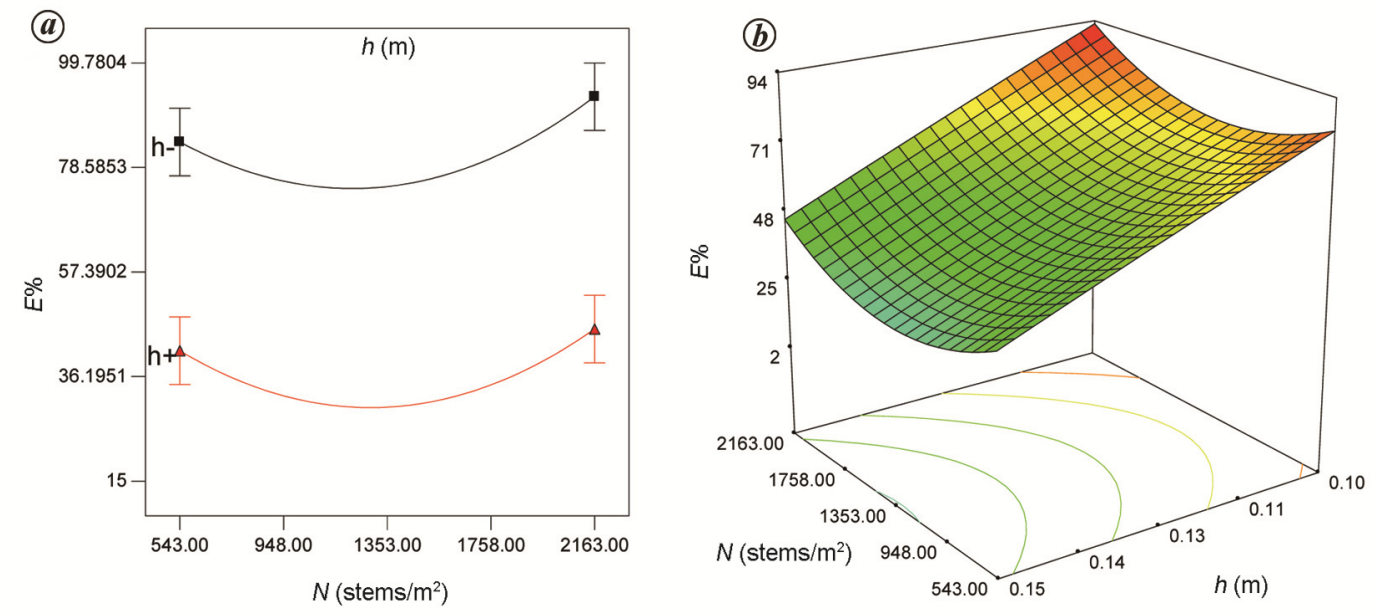

Figure 6. Interaction effect of $h$ and $N$ on $E \%$. $\boldsymbol{a}$, Two-way interaction effect; $\boldsymbol{b}$, Surface plot.

morphology ${ }^{8}$ and mechanical properties of vegetation such as shoot stiffness ${ }^{12}$ are related to wave dissipation. Also, it has been well established that the interactions of several process control parameters together rather than as an individual parameter alone are responsible for vegetation-induced wave attenuation ${ }^{12,49,50}$. In the present study, this result suggests that higher vegetation density combined with lower water depth causes a higher degree of wave attenuation, which is in agreement with the published results, such as an interaction effect of low $h$ and high $N$ on $E$ per cent.

Interaction effect of water depth and bed friction factor: The two-way interaction plot and surface plot shown in Figure $7 a$ and $b$ illustrate the effects of water depth $h$ and bed friction factor $f$ on $E \%$ respectively, at a fixed $T(2 \mathrm{~s})$ and $N\left(1353 \mathrm{stems} / \mathrm{m}^{2}\right)$. Although $f$ alone causes a positive effect (Table 2) on $E \%$, the $f$ and $h$ interaction cause a negative effect. The interaction between $h$ and $f$ on the response surface plot of the $E \%$ response indicates that an increase in $f$ due to changes in bed roughness from steel surface to fine sand (statistically represented from -1 and 0 ) and from fine sand to coarse pebbles (statistically represented from 0 and +1 ) results in improvement of $E \%$. When $h$ is at the lower level $(0.1 \mathrm{~m})$, the change in flume bed roughness factor from 0.012 (steel surface flume bed) to course pebbles bed flume $(0.025)$ results in an increase from $45 \%$ to $62 \%$ of $E \%$. At similar conditions, an increase in water depth from 0.10 to $0.15 \mathrm{~m}$, however, causes an marginal increase in $E \%$, i.e. less than $5 \%$. This result clearly shows that under the study conditions, water depth has a more dominant role in wave attenuation compared to all other parameters considered in this experiment, which is in good agreement with the results from flow studies ${ }^{51,52}$. For unidirectional flow, the greater the proportion of water depth over the canopy, 

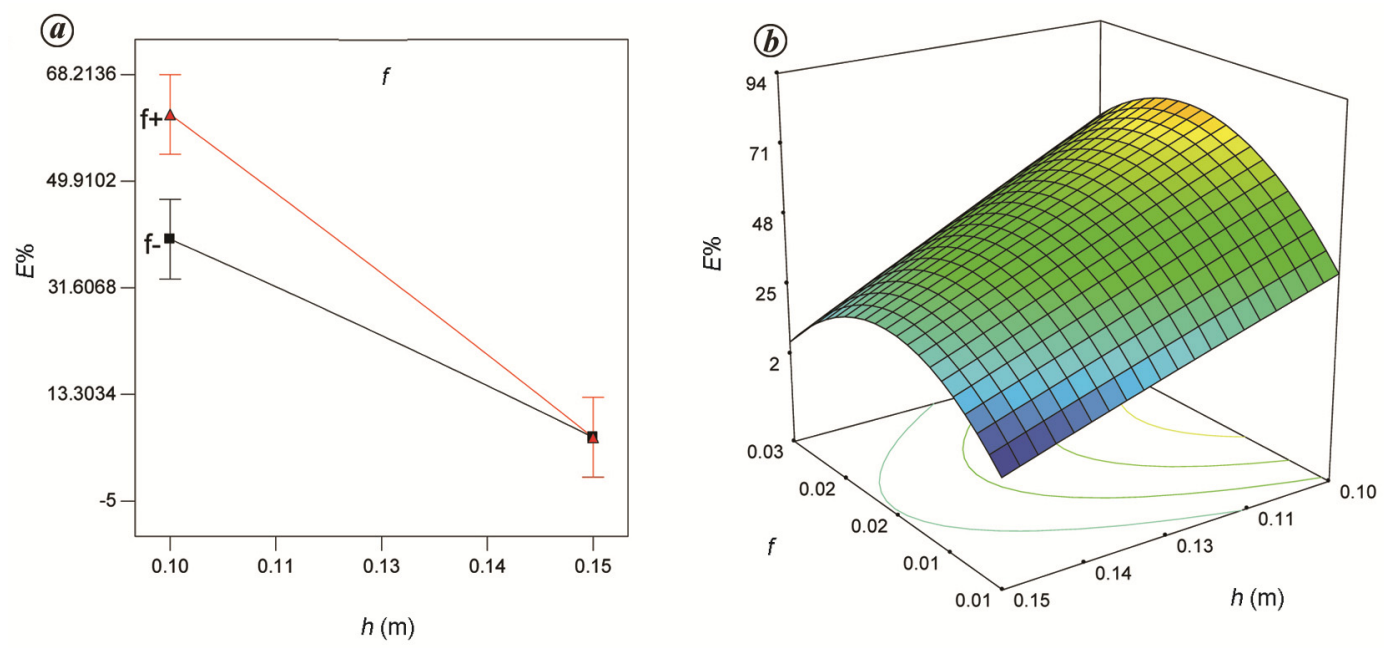

Figure 7. Interaction effect of $h$ and $f$ on $E \%$. $\boldsymbol{a}$, Two-way interaction effect; $\boldsymbol{b}$, Surface plot.
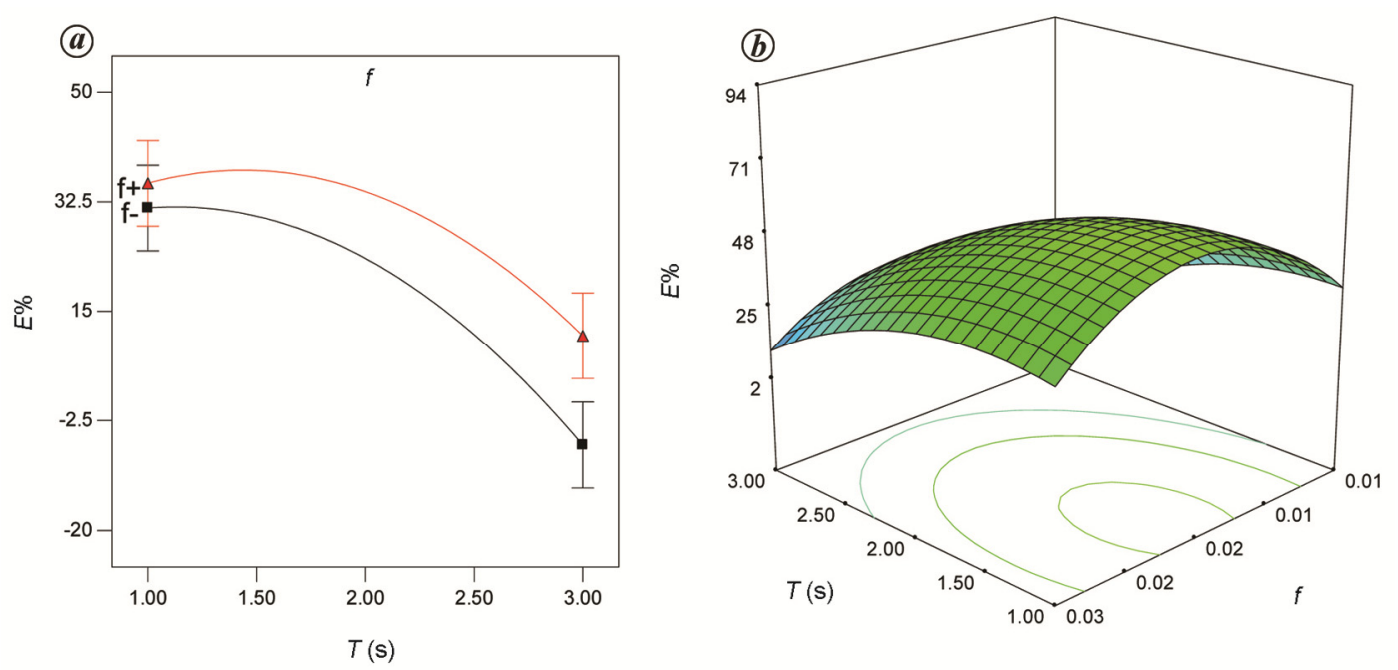

Figure 8. Interaction effect of $T$ and $f$ on $E \%$. $\boldsymbol{a}$, Two-way interaction effect; $\boldsymbol{b}$, Surface plot.

the less effective it is at reducing the flow. Also, the higher $f$ and shallow water depth cause higher dissipation of wave energy.

Interaction effect of wave period and bed friction factor: The developed empirical model (eq. (8)) also indicates that a statistically significant interaction effect exists between the wave period $T$ and bed friction factor $f$ on wave attenuation. Figure $8 a$ and $b$ graphically shows the interaction effects $T$ and $f$ on $E \%$ along the vegetation meadow. Although the cumulative of the interaction effect is directly proportional to $E \%$, an increase in $T$ from 1 to $3 \mathrm{~s}$ at the minimum $f(0.010)$ causes a decrease in $E \%$. The surface plot (Figure $8 b$ ) also indicates that the shorter wave period (1s) results in higher wave energy reduction percentage (75) for all the three different bed friction fac- tors. However, the lowest $f(0.010)$ at the longest wave period (3s) results in the lowest wave energy reduction percentage (nearly zero). On the contrary, the highest $f(0.025)$ at the shorter wave period (1 s) results in higher wave energy reduction percentage $(\approx 25)$. Among all other process control parameters considered in this study, the effect of wave period on dissipation has the most contradictory results in the literature. Möller et al. ${ }^{19}$ reported that salt marshes reduced wave energy at all wave periods by the same degree compared to the flat sand bottombased flows. However, other studies suggested that the vegetation-based wave attenuation is predominantly high wave period (high-frequency)-dependent ${ }^{16,45}$. Stratigaki et al. ${ }^{15}$ observed more than $35 \%$ reduction in wave height along the meadow due to a decrease in the wave period. The inverse nonlinear effect of wave period on energy 
variation (Figure $8 b$ ) along the vegetation meadow from the present study is in good agreement with the published results.

\section{Discussion}

Aquatic emergent plants are key players, generally acting as a buffer between the shore and open water; they significantly mitigate wave energy during and after a storm surge, before it reaches dry sand on the shore. In this study, it has been established that the aquatic emergent plants have the ability to reduce substantial wave energy, especially for small-orbital amplitude waves. Wave attenuation percentage increases under emergent conditions as the wave travels through the vegetation field, especially for small values of peak wave period. Also, it has been demonstrated that water depth is the major parameter and that wave attenuation is a function of vegetation characteristics such as plant density and also wave conditions such as incident wave period. These observations are in complete agreement with major findings from the literature. Enough work was performed by the heterospecific plant stems, resulting in a reduction of energy and thus smaller wave heights significantly affecting the waveinduced flows, especially for long wavelengths. In the present study, we have developed a statistical-based empirical model through DOE under controlled experimental conditions using laboratory flume. The developed model will help in understanding the individual as well as interaction effects of the process control variable in predicting wave attenuation $(E \%)$, the response variable. These results could be useful to meet the long-term needs of sustainable coastal protection and management systems. This will also help promote the use of natural protection measures, including restoration, management, re-planting of coastal vegetation/mangrove and shelterbelts, especially in the current scenario of rising sea levels and the increased numbers/intensities of storms, and the resulting increased hazard of coastal erosion.

\section{Conclusion}

Designed experimentation was conducted at a laboratory scale by employing a three-level four factor, central composite, face-centred RSM. The effect of four control parameters, viz. water depth, wave period, plant density and bed roughness factor on the wave energy reduction percentage $(E \%)$ was examined. A nonlinear empirical model was developed such that comparison and validation analysis of the model predictions against experimental data could be done. All the statistically significant primary and interaction effects of the operating parameters were examined and plotted on two-way interaction plots as well as 3D response surface plots. The results indicated that all the considered parameters have significant effects on wave energy attenuation individually as well as in combination under prescribed conditions. The results confirmed that $h$ has a main negative effect on $E \%$, while $N$ has a positive nonlinear effect, and the other two factors, $T$ and $f$ have no negative effects on linear. Water depth has the major contribution to wave attenuation as it has statistically significant two-way interactions with all the three other parameters ( $N, T$ and $f$ ). The RSM is effective for the prediction of wave energy reduction by heterospecific seagrass meadow, as ANOVA results indicate good agreement when comparing the experimental results with the model predictions at a high coefficient of determination $\left(R^{2}\right)$ of 0.9829 (with $P$-value $<0.05$ ).

1. Larkum, A. W. D., Orth, R. J. and Duarte, C. M., Seagrasses: Biology, ecology and conservation. Seagrasses: Biology, Ecology and Conservation, 2006, 1-691.

2. Manca, E., Cáceres, I., Alsina, J. M., Stratigaki, V., Townend, I. and Amos, C. L., Wave energy and wave-induced flow reduction by full-scale model Posidonia oceanica seagrass. Cont. Shelf Res., 2012, 50-51, 100-116.

3. Möller, I. et al., Wave attenuation over coastal salt marshes under storm surge conditions. Nature Geosci., 2014, 7, 727-731.

4. Specht, A., Gordon, I. J., Groves, R. H., Lambers, H. and Phinn, S. R., Catalysing transdisciplinary synthesis in ecosystem science and management. Sci. Total Environ., 2015, 534, 1-3.

5. Xu, S., Liu, Y., Wang, X. and Zhang, G., Scale effect on spatial patterns of ecosystem services and associations among them in semi-arid area: a case study in Ningxia Hui Autonomous Region, China. Sci. Total Environ., 2017, 598, 297-306.

6. Guannel, G. et al., Integrated modeling framework to quantify the coastal protection services supplied by vegetation. J. Geophys. Res.: Oceans, 2015, 120.

7. Vuik, V., Suh Heo, H. Y., Zhu, Z., Borsje, B. W. and Jonkman, S. N., Stem breakage of salt marsh vegetation under wave forcing: a field and model study. Estuarine Coastal Shelf Sci., 2018, 200, $41-58$.

8. Koch, E. W., Sanford, L. P., Chen, S. N., Shafer, D. J. and Smith, J. M., Waves in seagrass systems: review and technical recommendations (ERDC-TR-06-15), 2006, vol. 12, pp. 5-92.

9. Luhar, M. and Nepf, H. M., Wave-induced dynamics of flexible blades. J. Fluids Struct., 2016, 61, 20-41.

10. Feagin, R. A. et al., The role of beach and sand dune vegetation in mediating wave run up erosion. Estuarine Coastal Shelf Sci., 2019, 219, 97-106.

11. Koftis, T. and Prinos, P., Estimation of wave attenuation over Posidonia oceanica. Appl. Coastal Res., 2014, 4, 1-8.

12. Bouma, T. J. et al., Trade-offs related to ecosystem engineering: a case study on stiffness of emerging macrophytes. Ecology, 2005, 86, 2187-2199.

13. Best, Ü. S. N., Wegen, M. Van Der, Dijkstra, J., Willemsen, P. W. J. M. and Borsje, B. W., Do salt marshes survive sea level rise? Modelling wave action, morphodynamics and vegetation dynamics. Environ. Modell. Software, 2018, 109, 152-166.

14. Mendez, F. J. and Losada, I. J., An empirical model to estimate the propagation of random breaking and nonbreaking waves over vegetation fields. Coastal Eng., 2004, 51, 103-118.

15. Stratigaki, V. et al., Large-scale experiments on wave propagation over Posidonia oceanica. J. Hydraul. Res., 2011, 49, 31-43.

16. Bradley, K. and Houser, C., Relative velocity of seagrass blades: implications for wave attenuation in low-energy environments. J. Geophys. Res.: Earth Surf., 2009, 114, 1-13. 
17. Knutson, P. L., Brochu, R. A., Seelig, W. N. and Inskeep, M., Wave damping in Spartina alterniflora marshes. Wetlands, 1982, 2, 87-104.

18. Möller, I. and Spencer, T., Wave dissipation over macro-tidal saltmarshes: effects of marsh edge typology and vegetation change. J. Coastal Res., 2002, 36, 506-521.

19. Möller, I., Spencer, T., French, J. R., Leggett, D. J. and Dixon, M., Wave transformation over saltmarshes: a field and numerical modelling study from North Norfolk, England. Estuarine Coastal Shelf Sci., 1999, 49, 411-426.

20. Augustin, L. N., Irish, J. L. and Lynett, P., Laboratory and numerical studies of wave damping by emergent and nearemergent wetland vegetation. Coastal Eng., 2009, 56, 332-340.

21. Hu, Z., Suzuki, T., Zitman, T., Uittewaal, W. and Stive, M., Laboratory study on wave dissipation by vegetation in combined current-wave flow. Coastal Eng., 2014, 88, 131-142.

22. Vuik, V., van Vuren, S., Borsje, B. W., van Wesenbeeck, B. K. and Jonkman, S. N., Assessing safety of nature-based flood defenses: dealing with extremes and uncertainties. Coastal Eng., 2018, 139, 47-64.

23. Koftis, T., Prinos, P. and Stratigaki, V., Wave damping over artificial Posidonia oceanica meadow: a large-scale experimental study. Coastal Eng., 2013, 73, 71-83.

24. Suzuki, T., Zijlema, M., Burger, B., Meijer, M. C. and Narayan, S., Wave dissipation by vegetation with layer schematization in SWAN. Coastal Eng., 2012, 59, 64-71.

25. Tang, J., Shen, S. and Wang, H., Numerical model for coastal wave propagation through mild slope zone in the presence of rigid vegetation. Coastal Eng., 2015, 97, 53-59.

26. Anderson, M. E. and Smith, J. M., Wave attenuation by flexible, idealized salt marsh vegetation. Coastal Eng., 2014, 83, 82-92.

27. Jadhav, R. S., Chen, Q. and Smith, J. M., Spectral distribution of wave energy dissipation by salt marsh vegetation. Coastal Eng., 2013, 77, 99-107.

28. Paquier, A. E., Haddad, J., Lawler, S. and Ferreira, C. M., Quantification of the attenuation of storm surge components by a coastal wetland of the US Mid Atlantic. Estuaries Coasts, 2017, 40, 930-946.

29. Marsooli, R. and Wu, W., Numerical investigation of wave attenuation by vegetation using a 3D RANS model. Adv. Water Resour., 2014, 74, 245-257.

30. Paul, M., Rupprecht, F. and Möller, I., Plant stiffness and biomass as drivers for drag forces under extreme wave loading: a flume study on mimics. Coastal Eng., 2016, 117, 70-78.

31. Jagtap, T. G., Komarpant, D. S. and Rodrigues, R., Seagrasses of India: World Atlas of Seagrasses (eds Green, E. P. and Short, F. T.), 2003, pp. 101-108.

32. John, B. M., Shirlal, K. G. and Rao, S., Effect of artificial sea grass on wave attenuation - an experimental investigation. Aquat. Procedia, 2015, 4, 221-226.

33. Mani Murali, R., Ankita, M., Amrita, S. and Vethamony, P., Coastal vulnerability assessment of Puducherry coast, India, using the analytical hierarchical process. Nat. Hazard Earth Syst. Sci., 2013, 13, 3291-3311.

34. Arun Kumar, A. and Kunte, P. D., Coastal vulnerability assessment for Chennai, east coast of India using geospatial techniques. Nat. Hazards, 2012, 64, 853-872.
35. Sankari, T. S., Chandramouli, A. R., Gokul, K., Surya, S. S. M., and Saravanavel, J., Coastal vulnerability mapping using geospatial technologies in Cuddalore-Pichavaram coastal tract, Tamil Nadu, India. Aquat. Procedia, 2015, 4, 412-418.

36. Nobuhisa, K., Raichle, A. W. and Asano, T., Wave attenuation by vegetation. J. Waterway Port Coastal Ocean Eng., 1993, 119(1), 30-48.

37. Dalrymple, R. A., Kirby, J. T. and Hwang, P. A., Wave diffraction due to areas of energy dissipation. J. Waterway Port Coastal Ocean Eng., 1984, 110, 67-79.

38. Mullarney, J. C. and Henderson, S. M., Wave-forced motion of submerged single-stem vegetation. J. Geophys. Res.: Oceans, 2010, 115, 1-14.

39. Fonseca, M. S. and Cahalan, J. A., A preliminary evaluation of wave attenuation by four species of seagrass. Estuarine Coastal Shelf Sci., 1992, 35, 565-576.

40. Kuo, J. and den Hartog, C., Taxonomy and biogeography of seagrasses. In Seagrasses: Biology, Ecology, and Conservation, Springer, Netherlands, 2006, vol. 5, pp. 1-23.

41. El Shaffai, A., Field Guide to Seagrasses of the Red Sea Gland, IUCN, Switzerland, 2011.

42. Montgomery, D. C. and Runger, G. C., Applied statistics and probability for engineer. Eur. J. Eng. Educ., 1994, 19(3), 383.

43. Paul, M. and Amos, C. L., Spatial and seasonal variation in wave attenuation over Zostera noltii. J. Geophys. Res.: Oceans, 2011, 116, $1-16$.

44. Infantes, E., Orfila, A., Simarro, G., Terrados, J., Luhar, M. and Nepf, H., Effect of a seagrass (Posidonia oceanica) meadow on wave propagation. Mar. Ecol. Prog. Ser., 2012, 456, 63-72.

45. Lowe, R. J., Falter, J. L., Koseff, J. R., Monismith, S. G. and Atkinson, M. J., Spectral wave flow attenuation within submerged canopies: implications for wave energy dissipation. J. Geophys. Res.: Oceans, 2007, 112, 1-14.

46. Humbyrd, C. J. and Madsen, Predicting movable bed roughness in coastal waters. In Proceedings of 32nd Conference on Coastal Engineering, Shanghai, China, 2010, vol. 32, pp. 1-11.

47. Tschirky, P., Hall, K. and Turcke, D., Wave attenuation by emergent wetland vegetation. Coastal Eng., 2001, 276, 865-877.

48. Andersen, K. H., Mork, M. and Nilsen, J. E. Ø., Measurement of the velocity-profile in and above a forest of Laminaria hyperborea. Sarsia, 1996, 81, 193-196.

49. Huang, Z., Yao, Y., Sim, S. Y. and Yao, Y., Interaction of solitary waves with emergent, rigid vegetation. Ocean Eng., 2011, 38, 1080-1088.

50. Paul, M., Bouma, T. J. and Amos, C. L., Wave attenuation by submerged vegetation: combining the effect of organism traits and tidal current. Mar. Ecol. Prog. Ser., 2012, 444, 31-41.

51. Fonseca, M. S., Fisher, J. S., Zieman, J. C. and Thayer, G. W., Influence of the seagrass, Zostera marina L., on current flow. Estuarine Coastal Shelf Sci., 1982, 15, 351-364.

52. Fonseca, M. S. and Koehl, M. A. R., Flow in seagrass canopies: the influence of patch width. Estuarine Coastal Shelf Sci., 2006, 67, 1-9.

Received 14 October 2019; revised accepted 20 May 2020

doi: $10.18520 /$ cs/v119/i3/497-506 